\title{
Balloon dilation with triamcinolone intralesional injection successfully treated rectal stricture in a three-month kitten
}

\author{
Hee-Ryung Lee ${ }^{1,2, \dagger}$, Gareeballah Osman Adam ${ }^{1,3, \uparrow}$, Sei-Jin Lee ${ }^{4}$, Shang-Jin Kim ${ }^{1, *}$ \\ ${ }^{I}$ College of Veterinary Medicine, Jeonbuk National University, Iksan Campus, Iksan 54596, Korea \\ ${ }^{2}$ Hansarang Animal Hospital, Seoul 02880, Korea \\ ${ }^{3}$ Department of Veterinary Medicine and Surgery, College of Veterinary Medicine, Sudan University of Science and Technology, \\ Khartoum P.O. Box 204, Sudan \\ ${ }^{4}$ Korea Basic Science Institute Jeonju Center, Jeonju 54896, Korea
}

\begin{abstract}
This report describes a three-month-old Korean domestic kitten presented with dehydration and poor body condition. Physical examination revealed abdominal distension. Rectal diagnosis was unachievable due to the small rectum diameter. X-ray radiography and endoscopy confirmed presence of abdominal distension and indicated a stricture located $1.5 \mathrm{~cm}$ from the anus. A balloon was gently inserted into the rectum and inflated several times followed by triamcinolone injection. Four months later, same procedures were repeated. This report is the first to describe the use of balloon dilation of a rectal stricture followed by intralesional triamcinolone injection in a small cat with poor condition.
\end{abstract}

Keywords: balloon dilation, cat, rectal administration, intralesional injection, triamcinolone

*Corresponding author

Shang-Jin Kim

Department of Veterinary Pharmacology and Toxicology, College of Veterinary Medicine, Jeonbuk National University Iksan Campus, 79 Gobong-ro, Iksan 54596, Korea

Tel: $+82-63-850-0963$

Fax: +82-63-850-0910

E-mail: abbasj@jbnu.ac.kr

These authors contributed equally to this work.

ORCID:

Hee-ryung Lee

https://orcid.org/0000-0002-9982-7627

Gareeballah Osman Adam

https://orcid.org/0000-0002-8650-8117

Sei-jin Lee

https://orcid.org/0000-0001-8725-6639

Shang-jin Kim

https://orcid.org/0000-0002-9041-6565

Conflict of Interest

There is no conflict of interest.

Received: April 15, 2019

Revised: October 28, 2019

Accepted: December 2, 2019
Rectal stricture (RS) is a circumferential small rectal luminal diameter that may be due to an inflammatory process, fibrosis, trauma, or a growing tumor [1]. In kittens, a mild RS might be confused with atresia ani; thus, careful observation is needed to determine the cause. Atresia ani is a congenital disorder in which the anal membrane has failed to break down, whereas RS is not hereditary [2]. Narrowing of the rectum associated with RS can obstruct feces passage leading to disturbances in the digestive system. These disturbances depend on RS severity and the associated symptoms can vary but may encompass diarrhea, painful defecation, and constipation [3]. RS-related constipation may develop to obstipation depending on stricture severity [4]. Constipation can also lead to various complications that may endanger animal life, such as gut perforation, urinary-bladder displacement, and bowel obstruction $[5,6]$.

Diagnosis of RS can be achieved by digital rectal examination, insertion of a flexible balloon, X-ray radiography, or endoscopy [7]. RS is uncommon in kittens, but once diagnosed, practitioners may decide on surgical intervention [8]. However, several complications following surgical operations have been reported, such as infection, intra-abdominal abscess, enterocolitis, and rectal malfunction [9]. Previously, therefore, non-surgical approaches to RS treatment were suggested [10]. Recently, numerous cases have reported the use of non-invasive balloon and digital dilation methods for RS treatment [11-13]. Balloon dilation combined with triamcinolone injection is a particularly costeffective, reliable, and harmless method to treat strictures in the rectum [12].

Triamcinolone is a long-acting synthetic corticosteroid used superficially or systemically to treat several inflammatory and immunosuppressant conditions in the skin such as those related to allergy, digestive system diseases, and other causes [3,11].

Triamcinolone is safe with mild or no side effects, even when used in pregnant or young animals. Triamcinolone has been extensively used in combination with balloon dilation to treat RS [2]. This study describes a case of RS in a female kitten that was treated with balloon dilation and intralesional triamcinolone injection.

A three-month-old female Korean domestic short-hair cat weighing $0.6 \mathrm{~kg}$ 
was referred to Sarang Veterinary Clinic (Korea) for treatment of constipation, which had persisted for more than two months. Prior to presentation, constipation had been managed with lactulose $1 \mathrm{~mL}$ q $24 \mathrm{~h}$ PO (Duphalac syrup, Abbott Biologicals, USA). The owner reported signs that included difficulty and painful defecation, tenesmus, abdominal distention, decreased appetite, and loss of vitality. The physical examination revealed soft ribbon-like abdominal distension. Stool was observed at the anus. The cat was severely dehydrated ( $7 \%$ deficit) with a poor body condition, dry eye membrane, and minimal loss of skin elasticity. The cat had swollen and reddened rectal mucosa protruding from the anus, which could be penetrated digitally. However, further digital rectal examination could not be performed because of the limited anal size and small diameter of the rectal lumen.

Plain abdominal radiographs revealed severe diffuse colonic distention, without evidence of complete obstruction, and narrowing at the end of the anal canal (Fig. 1). Colonoscopy was performed under general anesthesia. A stricture located $1.5 \mathrm{~cm}$ from the anus, reduced the rectal lumen to a $1 \mathrm{~mm}$ diameter, restraining passage of the endoscope. Ring, smooth, and straight forceps with dimensions of $2.2 \mathrm{~mm}$ inside diameter and $3 \mathrm{~mm}$ outside diameter were used to widen the rectum. A headlight with high-resolution $2.5 \times / 420 \mathrm{~mm}$ binocular loupes (Heine Ltd., Herrsching, Germany) was used to improve visibility. Subsequent to forceps application, a deflated $2 \mathrm{~cm}$ long $15 \mathrm{~mm}$ dilatation balloon (2-way silicone Foley balloon catheter, UniBal, 8 French gauge [diameter $2.7 \mathrm{~mm}$, balloon capacity $3 \mathrm{~mL}$; Yushin Medical \& Trading Co., Seoul, South Korea) was advanced through the stricture under direct endoscopic guidance. We selected a $2 \mathrm{~cm}$ long balloon because the stricture was estimated to be located at $1.5 \mathrm{~cm}$ from the anus, while the balloon diameter and capacity were chosen because they allowed gradual filling to avoid complications. During the procedure, the balloon could be inserted and filled gradually, while leaving some portion outside the anus for movement control.

The balloon was inflated several times to two-thirds of the balloon's capacity $(0.67 \mathrm{~mL}$ saline was administered). Mild bleeding with no evidence of perforation was noted following removal of the balloon. The rectal and colonic mucosa proximal to the stricture appeared normal. After satisfactory dilatation had been achieved, $0.01 \mathrm{~mL}$ of $40 \mathrm{mg} / \mathrm{mL}$ triamcinolone (Woosung Hitec Co., Ltd., Korea) diluted to $10 \mathrm{~mL}$ with normal saline was injected quadrant of the stricture using a $0.3 \mathrm{~mL}$ insulin syringe. The final concentration of triamcinolone was $0.4 \mathrm{mg} / 10 \mathrm{~mL}$ normal saline.

The procedure was uneventful, and a post-procedure abdominal X-ray and contrast abdominal radiographs with iohexol (Omipaque, Amersham Health, Ireland) revealed the location of a narrowed region and a moderate diffuse colonic distention with no pneumoperitoneum. No distension was revealed (Fig. 2) and the kitten was discharged after $24 \mathrm{~h}$ with amoxicillin-clavulanate (Clavamox; Zeotis, Korea) to be administered at $15.6 \mathrm{mg} / \mathrm{kg}$ PO q $12 \mathrm{~h}$ for seven days.

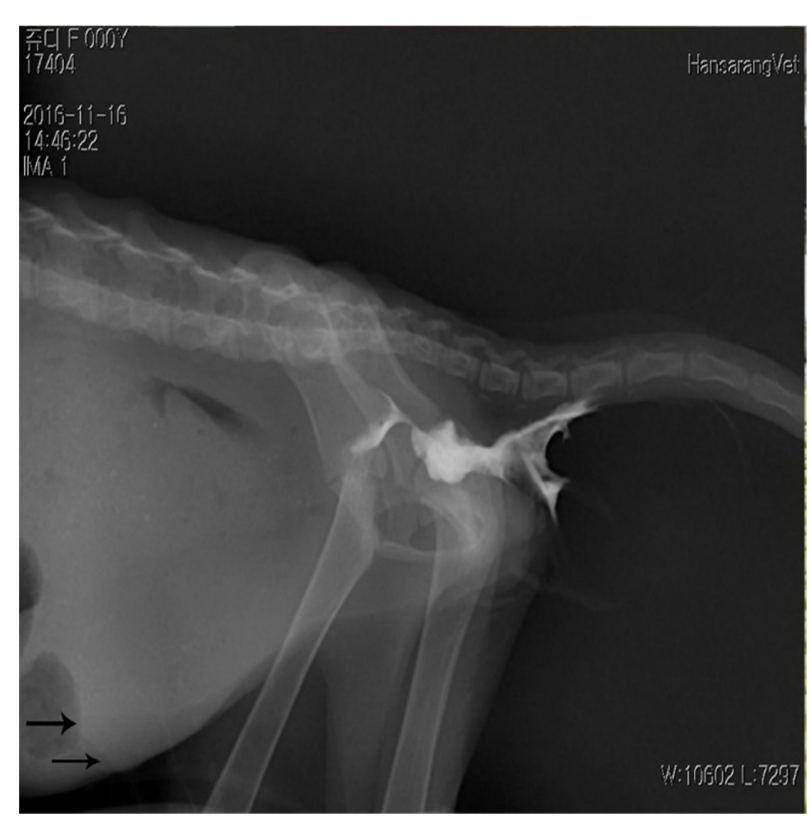

Fig. 1. Left lateral radiograph showing distended colon (arrows).

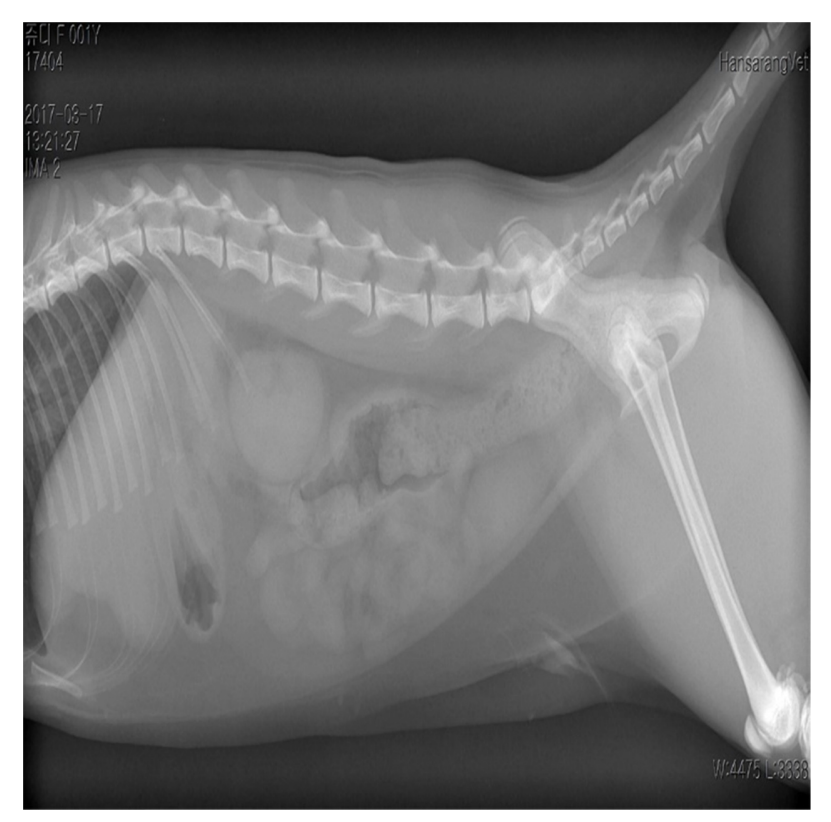

Fig. 2. Left lateral post-procedure radiograph showing neither pneumoperitoneum preformation nor colonic distension.

The pre-procedure soft ribbon-like stool characteristic was eliminated immediately after dilatation formation and X-ray radiography revealed neither abdominal distension nor penetration. Moreover, after treatment, the anal reflex was normal. The pre-procedure clinical signs including constipation disappeared immediately after treatment, and no complications were observed. Regardless, four months after the first treatment, constipation had recurred. Thus, we repeated the dilation and triamcinolone procedures and the amoxicillinclavulanate treatment as described above. Mild bleeding and 


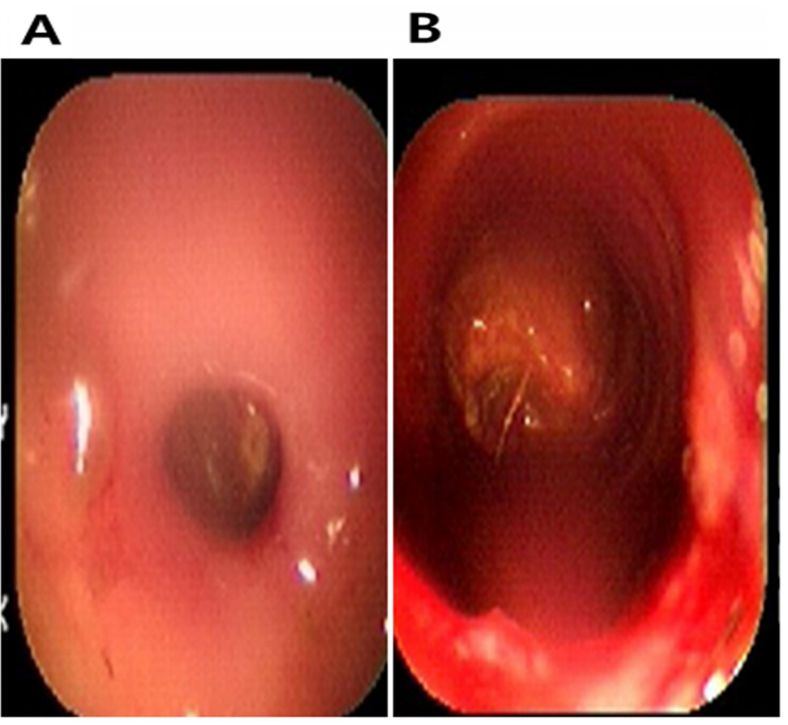

Fig. 3. Rectal lumen diameter before (A) and after (B) the dilatation procedure.

tearing were noted at the stricture; however, neither infection nor perforation was observed. Post-procedure, the stricture lumen had widened to a $10 \mathrm{~mm}$ diameter, confirmed via colonoscopy, a marked improvement over the $1 \mathrm{~mm}$ lumen diameter before the first procedure (Fig. 3A and B). Fig. 3A shows that the lumen of the rectum was partially occult, indicated by the small diameter of the anal canal, while Fig. 3B shows the lumen after stenosis repair, revealing that the anal canal was considerably widened, which allowed for an easier approach during endoscopy than that prior to the procedures. The second procedure also led to the immediate normalization of defecation. At 12 months post-procedures, the cat was stricture-free, as confirmed by repeated flexible endoscopy, and the cat was clinically unremarkable two years after the second procedure.

An RS indicates a decreased diameter of the rectum lumen and such strictures are associated with risks of constipation and obstipation, requiring surgical intervention. However, postoperative complications may occur [14].

One of the non-invasive approaches used for the treatment of $\mathrm{RS}$ is lumen widening using an expandable balloon or bougie, which is a cylinder of rubber or plastic inserted into a body passageway [15]. In this report, we used a flexible rubber balloon and endoscopic guiding to increase the lumenal diameter of the stricture-restricted rectum in the kitten. The procedure was safe and the results satisfactory. Similar procedures have been performed in humans and animals with great success and are reported to be safe $[16,17]$. Such strictures are typically composed of fibrous and collagen-rich tissue and balloon dilation produces its effects as a result of mechanical forces on the protruding tissue and via shearing effects $[18,19]$, hence increasing lumen diameter.

In this case, we injected triamcinolone directly into the stricture site. Singh et al. [18] reported that intralesional injection of an anti-inflammatory such as triamcinolone can increase the success rate when treating upper and lower gastrointestinal Crohn's disease strictures. Furthermore, triamcinolone is used for the treatment of peptic stricture of the esophagus due to its reported effectiveness in lesion healing [20]. The mechanism of action of triamcinolone in the healing of the stricture has not been fully described. However, it is thought to be due to its ability to elicit collagenase expression with the associated collagen breakdown leading to scar reduction $[21,22]$.

Using antibacterial agents post-operatively is a common practice to combat bacterial infection. Jessica and co-workers used amoxicillin clavulanate clavulanate to prevent bacterial attack for ten days after discharge [16,21]. In this case, we used amoxicillin clavulanate for only seven days because of the kitten's low body weight, age, and poor overall condition.

Relapse of RS may occur; therefore, secondary or multiple repeat procedures have been used when applying the balloon dilation method to produce an optimal or improved lumen diameter and, subsequently, spontaneous defecation $[7,23]$. In this study, we repeated the procedure after recurrence of constipation in order to produce a suitable lumen diameter and avoid complications. The status of the kitten was followed for two years after the first procedure, during which no indications of RS recurrence were noticed, and normal defecation ensued; these observations indicate the success of the procedures and antibiotic treatments.

Mild bleeding due to minor damage to small capillaries in the mucosa of the bowel was noticed in this case, and similar observations were reported in several cases involving the same procedure $[8,24]$. However, compared with the results of surgical RS treatments, several complications such as infection, hemorrhage, and perforation were avoided because balloon dilation is a relatively gentle, non-invasive procedure. In this case report, we emphasized that balloon dilation with triamcinolone intralesional injection is safe and satisfactory when applied to a severely dehydrated kitten in poor condition. Additionally, we show that the procedure can be repeated to normalize defecation in such an emaciated kitten without the development of complications. Most of the previously published cases have reported on adult animals or humans with poor to good body condition [25,26], not on severely dehydrated young animals. In this case, we have shown that balloon dilation in conjunction with triamcinolone intralesional injection can be used in kittens in a severely dehydrated poor condition; regardless, such procedures should be performed carefully to avoid possible complications.

In conclusion, endoscopically-guided balloon dilation in conjunction with intralesional injection of triamcinolone is a procedure that can be used successfully for the treatment of RS stricture in a kitten. The method is effective, safe, can be accomplished quickly, and can produce a satisfactory result without complications. The procedure resulted in normal defecation in the kitten after long-term follow-up. 


\section{Acknowledgments}

We thank the staff of Hansarang Animal Hospital, Seoul, South Korea for technical and clinical assistance. The Ministry of Science and Technology supported this work, Republic of Korea (NRF-2018R1A2B6003332 and NRF-R1D1A1 B07042552).

\section{References}

1. Washabau RJ. Chapter 1: integration of gastrointestinal function. In: Washabau RJ, Day MJ (eds.). Canine and Feline Gastroenterology. 1st ed. pp. 1-31. W.B. Saunders, Saint Louis, 2013.

2. Karanikas M, Touzopoulos P, Mitrakas A, Zezos P, Zarogoulidis P, Machairiotis N, Efremidou E, Liratzopoulos N, Polychronidis A, Kouklakis G. Benign post-radiation rectal stricture treated with endoscopic balloon dilation and intralesional triamcinolone injection. Case Rep Gastroenterol 2012;6: 583-589.

3. Houghton G, Matthews RA. Immunosuppression of carp (Cyprinus carpio L.) to ichthyophthiriasis using the corticosteroid triamcinolone acetonide. Vet Immunol Immunopathol 1986; 12:413-419.

4. Placer C, Urdapilleta G, Markinez I, Mugika F, Múgica JA, Elósegui JL, Murgoitio J, Irazusta M, Enríquez-Navascués JM. Benign anastomotic strictures after oncologic rectal cancer surgery. Results of treatment with hydrostatic dilation. Cir Esp 2010;87:239-243.

5. Garisto JD, Campillo L, Edwards E, Harbour M, Ermocilla R. Giant fecaloma in a 12-year-old-boy: a case report. Cases J 2009;2:127.

6. Cheng M, Ghahremani S, Roth A, Chawla SC. Chronic constipation and its complications: an interesting finding to an otherwise commonplace problem. Glob Pediatr Health 2016;3:2333794X16648843.

7. Lamoureux A, Maurey C, Freiche V. Treatment of inflammatory rectal strictures by digital bougienage: a retrospective study of nine cases. J Small Anim Pract 2017; 58:293-297.

8. Chavkin JA, Spector DJ, Stanley SW. Balloon dilation and intralesional steroid for benign rectal stricture management in a cat. J Feline Med Surg 2010;12:663-665.

9. Zwart K, Van Ginkel DJ, Hulsker CC, Witvliet MJ, Van Herwaarden-Lindeboom MY. Does mechanical bowel preparation reduce the risk of developing infectious complications in pediatric colorectal surgery? A systematic review and metaanalysis. J Pediatr 2018;203:288-293.e1.

10. Skreden K, Wiig JN, Myrvold HE. Balloon dilation of rectal strictures. Acta Chir Scand 1987;153:615-617.
11. Kay AT, Bolt DM, Ishihara A, Rajala-Schultz PJ, Bertone AL. Anti-inflammatory and analgesic effects of intra-articular injection of triamcinolone acetonide, mepivacaine hydrochloride, or both on lipopolysaccharide-induced lameness in horses. Am J Vet Res 2008;69:1646-1654.

12. Araujo SE, Costa AF. Efficacy and safety of endoscopic balloon dilation of benign anastomotic strictures after oncologic anterior rectal resection: report on 24 cases. Surg Laparosc Endosc Percutan Tech 2008;18:565-568.

13. Di ZH, Shin JH, Kim JH, Song HY. Colorectal anastomotic strictures: treatment by fluoroscopic double balloon dilation. J Vasc Interv Radiol 2005;16:75-80.

14. Kunitake H, Poylin V. Complications following anorectal surgery. Clin Colon Rectal Surg 2016;29:14-21.

15. Bonadio WA, Jona JZ, Glicklich M, Cohen R. Esophageal bougienage technique for coin ingestion in children. J Pediatr Surg 1988;23:917-918.

16. Webb CB, McCord KW, Twedt DC. Rectal strictures in 19 dogs: 1997-2005. J Am Anim Hosp Assoc 2007;43:332-336.

17. Westerman ME, Parker WP, Viers BR, Rivera ME, Karnes RJ, Frank I, Tarrell R, Thapa P, Thompson RH, Tollefson MK, Boorjian SA. Malignant ureteroenteric anastomotic stricture following radical cystectomy with urinary diversion: Patterns, risk factors, and outcomes. Urol Oncol 2016;34: 485.e1-485.e6.

18. Singh VV, Draganov P, Valentine J. Efficacy and safety of endoscopic balloon dilation of symptomatic upper and lower gastrointestinal Crohn's disease strictures. J Clin Gastroenterol 2005;39:284-290.

19. Ruetzler K, Krafft P, Frass M. Airway management in intensive care medicine. In: Hagberg CA (ed.). Benumof and Hagberg's Airway Management. 3rd ed. pp. 916-954.e917. W.B. Saunders, Philadelphia, 2013.

20. Griffith BH. The treatment of keloids with triamcinolone acetonide. Plast Reconstr Surg 1966;38:202-208.

21. Daane S, Toth BA. Plastic Surgery Secrets Plus. 2nd ed. pp. 120-122. Mosby, Philadelphia, 2010.

22. Ketchum LD, Smith J, Robinson DW, Masters FW. The treatment of hypertrophic scar, keloid and scar contracture by triamcinolone acetonide. Plast Reconstr Surg 1966;38:209218.

23. Lavy A. Triamcinolone improves outcome in Crohn's disease strictures. Dis Colon Rectum 1997;40:184-186.

24. Gunjan D, Sharma V, Rana SS, Bhasin DK. Small bowel bleeding: a comprehensive review. Gastroenterol Rep (Oxf) 2014;2:262-275.

25. Brower RA, Freeman LD. Balloon catheter dilation of a rectal stricture. Gastrointest Endosc 1984;30:95-97.

26. Hidas G, Gibbs D, Alireza A, Khoury AE. Management of rectal stenosis with endoscopic balloon dilatation. J Pediatr Surg 2013;48:e13-e16. 